\title{
Behavioural profiling of autism connectivity abnormalities - Erratum
}

William Snyder and Vanessa Troiani

\section{Keywords}

Autism spectrum disorder; neuroimaging; fMRl; meta-analysis.

\section{Copyright and usage}

(c) The Author(s) 2020. This is an Open Access article, distributed under the terms of the Creative Commons Attribution licence (http://creativecommons.org/licenses/by/4.0/), which permits unrestricted re-use, distribution, and reproduction in any medium, provided the original work is properly cited.

DOI: https://doi.org/10.1192/bjo.2019.102, Published online by Cambridge University Press, 22 January 2020
Author William Snyder's affiliation erroneously included $\mathrm{PhD}$ in his biography. The correct biography is:

William Snyder, Student, Program in Neuroscience, Bucknell University; Research Assistant, Autism and Developmental Medicine Institute, Geisinger, USA

This article was incorrectly published with an extra asterisk in Figure 4 . The correct figure is below.

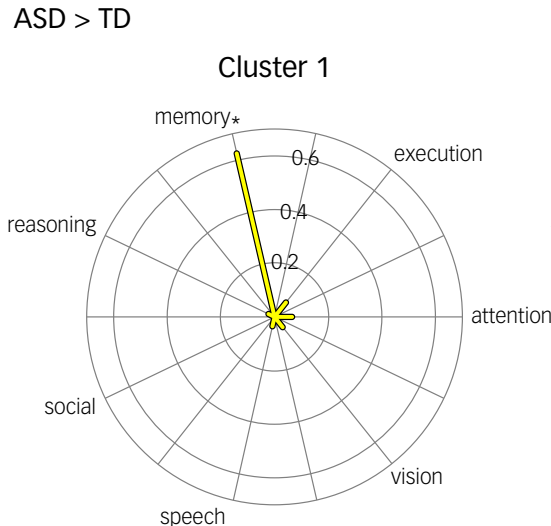

TD $>$ ASD
Cluster 2

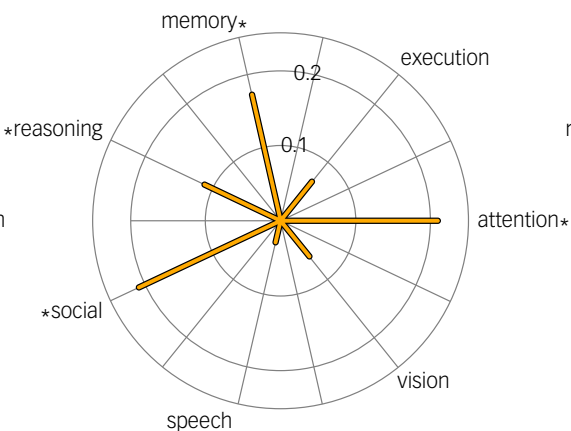

Cluster 3

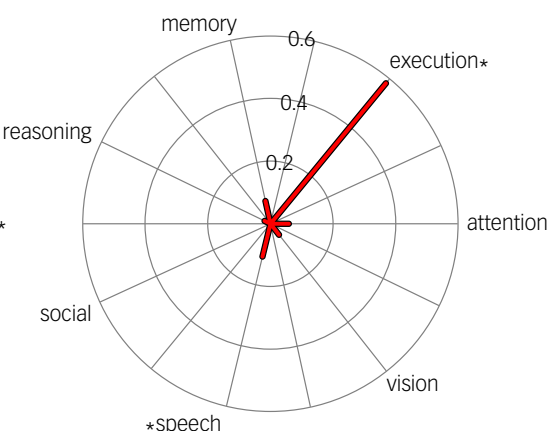

Cluster 1

Cluster 2

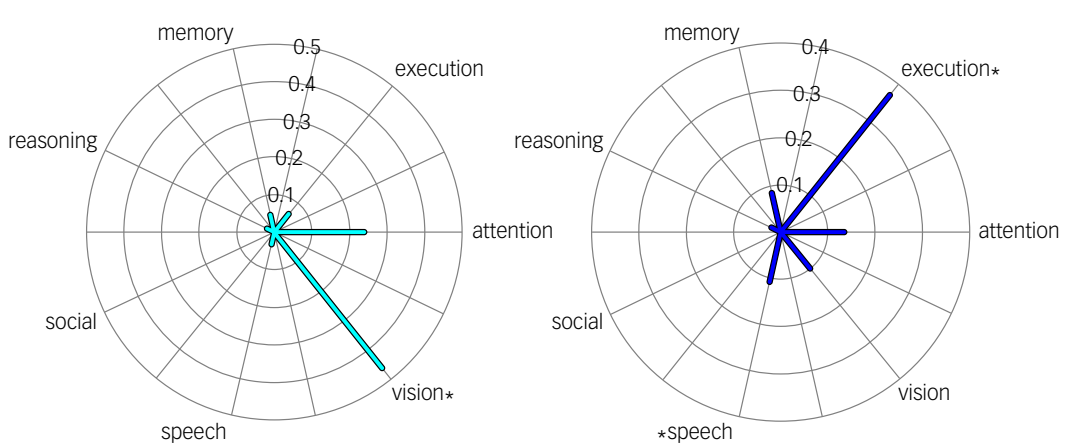

Fig. 4

The publisher sincerely apologises for this error.

\section{Reference}

1 Snyder, W., \& Troiani, V. (2020). Behavioural profiling of autism connectivity abnormalities. BJPsych Open, 6(1), E11. doi:10.1192/bjo.2019.102 